\title{
ELECTRICAL ENERGY CONSERVATION IN A COMMERCIAL BUILDING WITH SYSTEMS AUTOMATION
}

\author{
Joel R. Pinto, Cícero C. Moraes, Augusto F. Brandão Jr. \\ Polytechnic School - University of São Paulo - CP 61548 CEP 05508-900 SPauloSP-Brazil \\ Facens - Engineering School of Sorocaba - Sorocaba SP - Brazil \\ joel@facens.br cicero@pea.usp.br brandao@pea.usp.br
}

\begin{abstract}
This is a case study of the utilization of automation equipments and supervisory system in a commercial building and the consequent energy consumption reduction. The main characteristics of the automation architecture, control stations and of the communication network are described The six-floor building is fed by two $1000 \mathrm{kVA}$ and one $300 \mathrm{kVA}$, $13,8 \mathrm{kV} / 220 \mathrm{~V}$ transformers, about 1000 points are monitored. The automated network generates economy and energy conservation mainly in the lighting and HVAC systems. The annual load curves for the years 1994 to 1996 show decreases both in energy consumption as well as in the demand values.
\end{abstract}

\section{INTRODUCTION}

A necessary consequence of the implementation of automated systems in a building is the decrease of energy consumption. The programs of energy conservation can be incorporated either in the controllers or increasing the equipment's efficiencies, for example updating lighting fixtures and electric motors technology. The financial payback can be substantial and may partially offset the total installation cost. The energy conservation program begins with a list of the necessities of the building in the architecture project and finishes with its utilization, the persons who use the edification supposed to have comfort without waste.

Major energy savings can be carried out by changes in the lighting system. In a commercial building lights remain on even in unoccupied periods, which can achieve $75 \%$ of the time ${ }^{3}$. Economy comes from either the use of more efficient fluorescent lamps, ballast's and luminaries or the lighting control program. The lighting control can be carried out by a simple on-off control for occupiedunoccupied situations, or monitoring the lighting levels in the perimeter zone of the building and adding to the natural lights the artificial ones in order to maintain the desired lighting levels. Another important source of energy savings is through reduced run time of HVAC systems, which can be obtained reducing fan or pump operations. 


\section{BUILDING AUTOMATION SYSTEM ARCHITECTURE}

Accordingly to the current philosophy of building automation ${ }^{2}$, there will be independence between the local supervision and control stations and the central computer. Although physically independent, the stations are interconnected, with an architecture that is flexible, changing with the application and disposition ${ }^{1}$.

The edification must have a system of digital automation, integrated and geographically distributed. The components will be linked up by a communication network, which maintains the functional division between the utility supervision and control on one side, and security on the other ${ }^{6}$. The integration of the various subsystems in one is necessary to guarantee its inter-operability in automatic functions like the equipment's drive in the case of fire or intrusion detection. The building automation system (Figure 1) is composed by:

- Operating Stations (OS)

- Master Control Stations (MCS)

- Local Control Stations (LCS)

- Gateways

- Data Communication Network

- Maintenance Portable Terminal

\section{Operating Stations (OS)}

The system operation is accomplished throughout two conventional microcomputers. The supervisory systems centralize the operations, either of the utilities group and the maintenance or of the security and fire detection. The first microcomputer is the station of operation and maintenance of the utilities. It is responsible for the supervision and control of the electric power system, the management of the electric energy and of the air conditioning system, and the preventive and corrective maintenance. The other one is the security operation station, where the fire detection and alarm subsystems, the access control, the intrusion detection and TVCC monitoring are carried out.

The man-machine software is graphical and the operator can navigate into different screens, which represent the geometry of the building with different levels of zooming. The operating stations present as their functions:

- to monitor analog values as temperatures, electric currents, voltages, pressures;

- to generate (screen and printed) graphs of these values;

- to adjust set-points in the control loops;

- $\quad$ to adjust minimum and maximum values associated to the analog values above;

- to monitor the status of detectors, motors, switches, electromechanical devices;

- to switch on and off machines, lights and circuits, valves and dampers;

- to define automatic programs with the use of software;

- to select operation modes of equipment's and of subsystems;

- to monitor and to recognize alarms;

- to print various types of reports. 


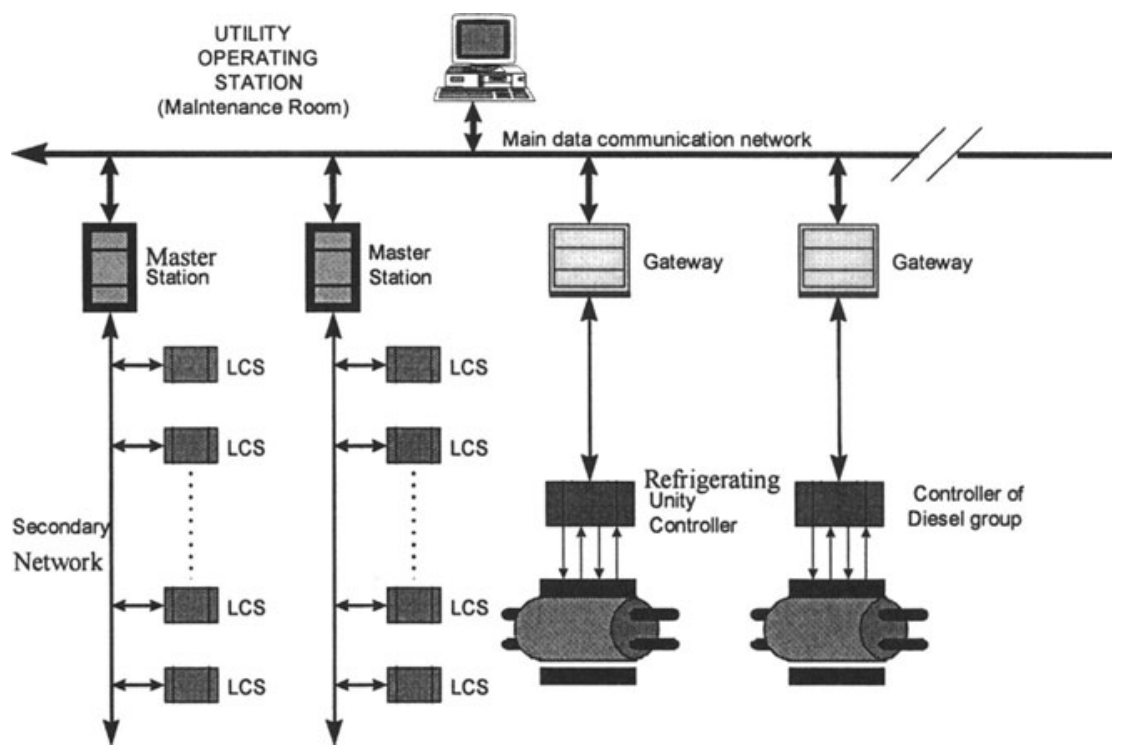

Figure 1 - General Architecture of a Building Automation System - Utilities and Maintenance Control

\section{Master Control Stations}

The operating stations are linked to the master control stations throughout the main data communication network, which can be, for example, Ethernet or Novell. The master control stations control smaller parts of the automation system by the secondary networks with slower transmission data velocities than the previous one. The partial system database is there. They present an I/O to interface with the supervised equipments, which can be either analog or digital. Each station is configured and can receive additional local and expansion modules. They can control one or more secondary networks where the local control stations are connected. The database is available to all operating stations and to the portable terminal. The master station is autonomous, in the sense that they continue to operate even in failure of the operating stations or of the main network.

\section{Local Control Stations}

They are small stations, with few I/O's, with the purpose of controlling specific devices as lighting, fan coils, pumps, or the remote expansion of master's stations. They are placed near or inside the controlled equipments and they are connected to the master station by the secondary networks. They are also autonomous in the sense that they continue operating even in the failure of the master stations where they are connected. 


\section{Portable Terminal}

It is a notebook used for maintenance purposes and functionally it is identical and has the same software of the operating stations. It can also be connected to the main network.

\section{Others}

It is complemented (Figure 2) by other subsystems as:

- system for fire detection and alarm

- television closed circuit (TVCC)

- ambient sound system

- access control

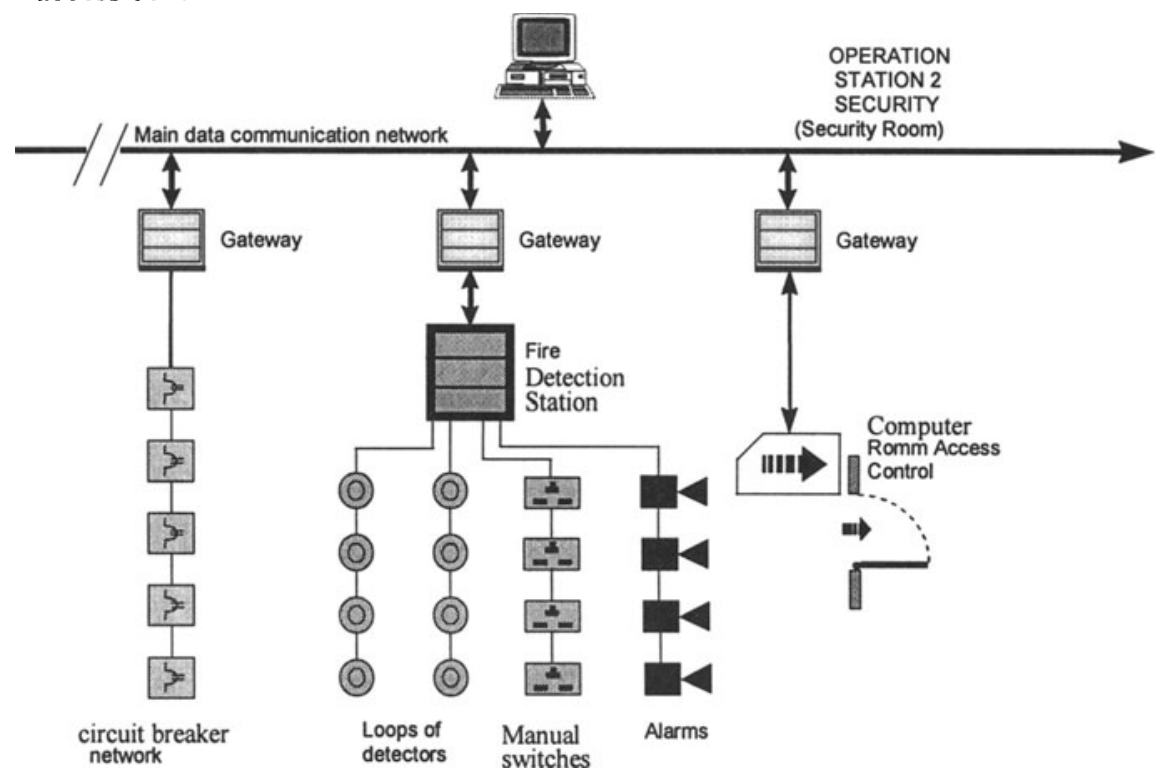

Figure 2 - General Architecture of a Building Automation System - Fire Detection and Security (Access Control)

\section{BUILDING AUTOMATION SYSTEM DESCRIPTION - SPECIFICS}

The system for supervision and control was implemented in the six floors of a commercial building, mainly used for office and commercial purposes, about 1000 points being monitored and/or controlled. The main electric loads are lighting, air conditioning and microcomputers.

\section{Electric Power System}

The substation receives the primary voltage at the level of $13.8 \mathrm{kV}$ and reduces it to the low voltage of $220 / 127 \mathrm{~V}$ by means of two $1000 \mathrm{kVA}$ transformers. There is an 
additional $300 \mathrm{kVA}$ transformer feeding the no-breaks. The following points are monitored/automated:

- $\quad$ active and reactive power in the substation;

- demand and power factor;

- voltage levels at the batteries and at the no-break;

- failures in the battery loader;

- temperature and oil level alarms;

- under and overvoltage alarms;

- $\quad$ status of switches, circuit breakers and relays at $13.8 \mathrm{kV}$;

- loss of voltage in the command circuits of the substation;

- $\quad$ voltage, currents and power in the $13.8 \mathrm{kV}$ feeders;

- $\quad$ status of the low voltage power circuit breakers;

- voltage, currents and power in the low voltage busbars.

There is one $300 \mathrm{kVA}$ no-break at the side of the substation feeding all the computer equipments of the building as well as the emergency lighting. One $500 \mathrm{kVA}$ diesel group is also installed near the substation and in case of necessity - failure in the power system - it can feed the no-break and the air conditioning loads of the main points. There are separated low voltage busbars for normal and emergency circuits, the last one being connected to the no-break. There are different circuits for:

- normal condition busbar;

- $\quad$ lighting and outlets bus-way;

- $\quad$ air conditioning bus-way;

- emergency busbar;

- emergency lighting bus-way;

- $\quad$ outlets for computer equipments busway;

- automation system.

\section{Lighting}

After the retrofit the lighting system is composed by 7836 fluorescent $32 \mathrm{~W}$-lamps with electronic ballasts. At the areas near the windows the ballast's can adjust automatically based on photocells taking part of the daylight. Part of the ballast is fed by the no-break, which constitutes the emergency lighting system: in the central corridor at each floor; at the stairs and lavatories; at the electricity and communication "shaft". After the modifications, the electric load decreased from $37.7 \mathrm{~W} / \mathrm{m}^{2}$ to $13.5 \mathrm{~W} / \mathrm{m}^{2}$.

\section{Air Conditioning}

There is a central of cold water that is composed by two chillers (300TR) and by tanks for thermo accumulation (150 TR). The refrigerating unity controller is connected to the Building Automation System by a serial interface, via gateway. The local controller performs all the machine functions including the temperature of the water. The following informations are taken:

- in and out water temperature, in the cold water and in condensation circuits;

- operational status of each machine and compressor;

- the water flow;

- machine failures. 
The building automation system controls:

- unity start and stop;

- cold water set-point;

- machine capacity limit.

All ambient zones (work zones) are controlled based in the variable air volume systems (VAV) ${ }^{4}$, which allow the variation of airflow accordingly with the thermal load. Each VAV box possess an individual microprocessor controller, which directs the damper motor based on the ambient temperature and on the differential pressure measured in the box. The VAV controllers are linked to the Building Automation System and, particularly, to the air conditioning controllers. Each air conditioning device has a microprocessor controller, which is linked to the Building Automation System, and has the following duties:

- machine start/stop command;

- failure monitoring - overload;

- $\quad$ air temperature control, by means of the frequency inverter of the fan;

- external air admission control, by means of a motorized damper.

\section{SYSTEM IMPLEMENTATION}

The implementation of the automation system in the building began in 1994. The working hours changed from the interval $8 \mathrm{am}$ to $6 \mathrm{pm}$ to new interval $7 \mathrm{am}$ to $10 \mathrm{pm}$, this 5 hours increase due to the new digital equipment's and to the conditions of flexibility and security obtained with systems automation. The objective during the first semester was to adjust the equipment's operation and to collect data in order to base future decisions. In 1995 the studies went on, although more attention was paid to the lighting programs and to the best hours for air conditioning utilization. Also, there was an analysis of the potential of electric energy economy when taking an effective energy management program. From this analysis it could be concluded:

(a) the implementation of the building automation program made possible a modest energy economy in the first semester, the main objective was of adjusting the equipment's operation and collecting data;

(b) using the collected data in the programming of the lighting programs and to define the periods for the air conditioning, the economy of electric energy was in the first year about 1,359 MWh, which means an economy yet modest of $\mathrm{R} \$ 54,149.00 /$ year (approximate exchange rate of $\$ R 1.20$ to US\$1.00);

(c) there was a reasonable reduction of electric energy consumption, mainly in the period off-peak, although a better performance for the peak hours should be pursued;

(d) although the reduction in electric energy consumption it could be noticed by the load factors that an effective energy management was not implemented yet;

(e) both the demands, peak and off-peak, were reduced, but due to the commercial contract with the electric company (peak demand of $800 \mathrm{~kW}$, off-peak demand of $1400 \mathrm{~kW}$ ), a significant economy in that year was not yet possible;

(f) although the power factor already obeyed the legislation limits, the switching on/off of the capacitors for power factor correction began to be made 
automatically, what means a better control for the power factor of the building and a longer life for the capacitors.

Some operational procedures were changed in order to achieve better results in the energy conservation program, as for example:

(a) modification in the building thermal load which improves the demand;

(b) minimum utilization of the electrical energy in the peak hours, with the use of ice accumulation;

(c) modifications in the set points of the building automatic management for the air conditioning, accordingly to the sunlight at the rooms;

(d) modifications in the renewed commercial contract with the electric company, changing the values of: peak demand from $800 \mathrm{~kW}$ to $600 \mathrm{~kW}$, off-peak demand from $1400 \mathrm{~kW}$ to $1200 \mathrm{~kW}$.

There was yet a large margin in the power values in the new contract, but it was considered a foreseeable future load increase. Figures 3 and 4 show the behavior of the electric energy consumption and figures 5 and 6 show the behavior of the electric demand for the years 1994, 1995 and 1996. A clear decrease from 1994 values (in blue) to 1995 and 1996 values (red and green) can be noticed.

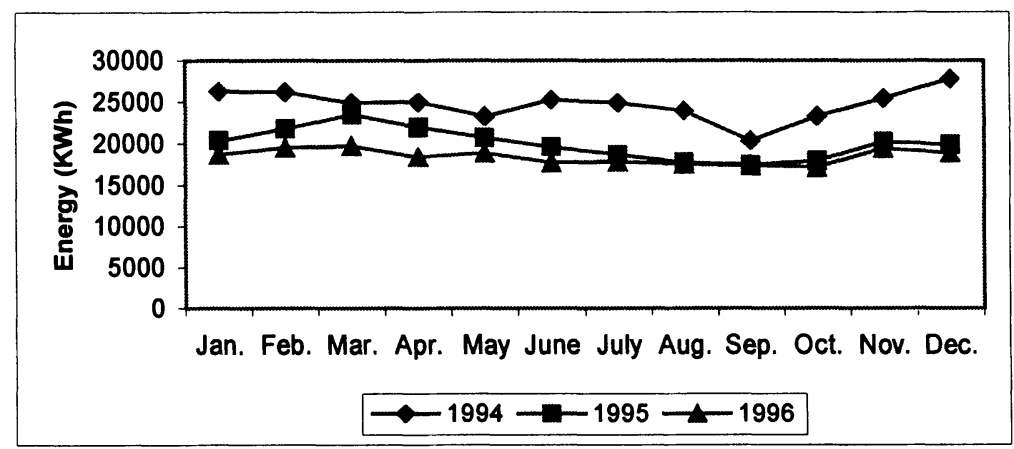

Figure 3 Energy consumption at peak hours

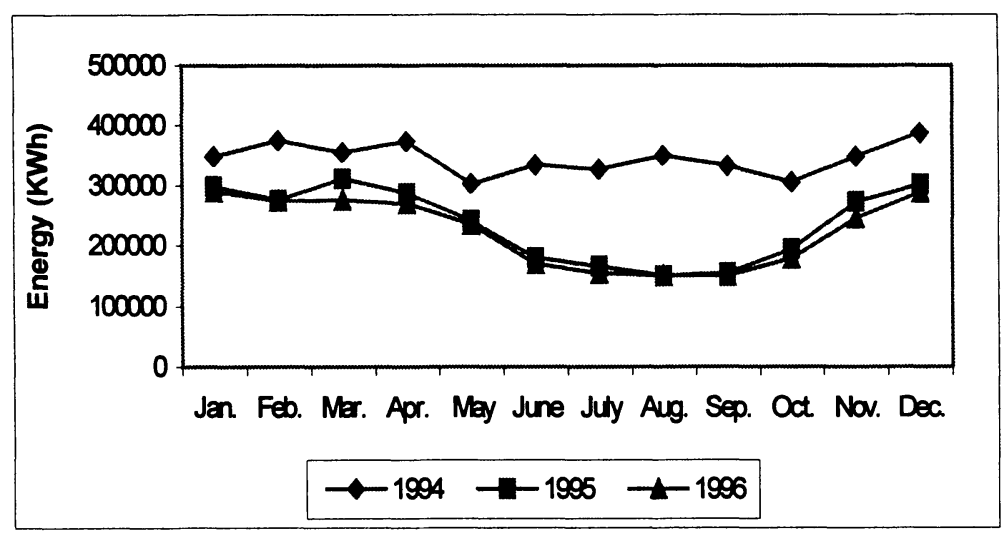

Figure 4 Energy consumption at off-peak hours 


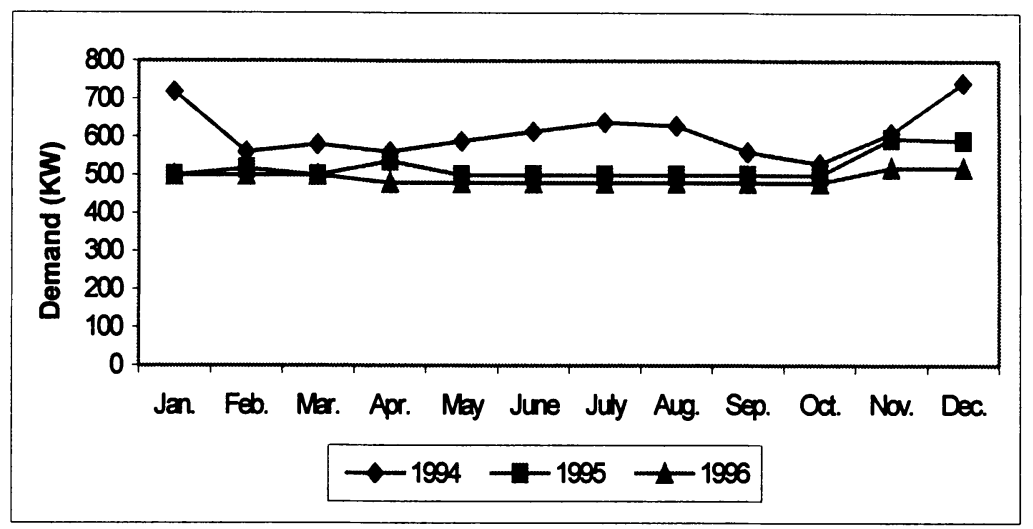

Figure 5 Peak hours demand

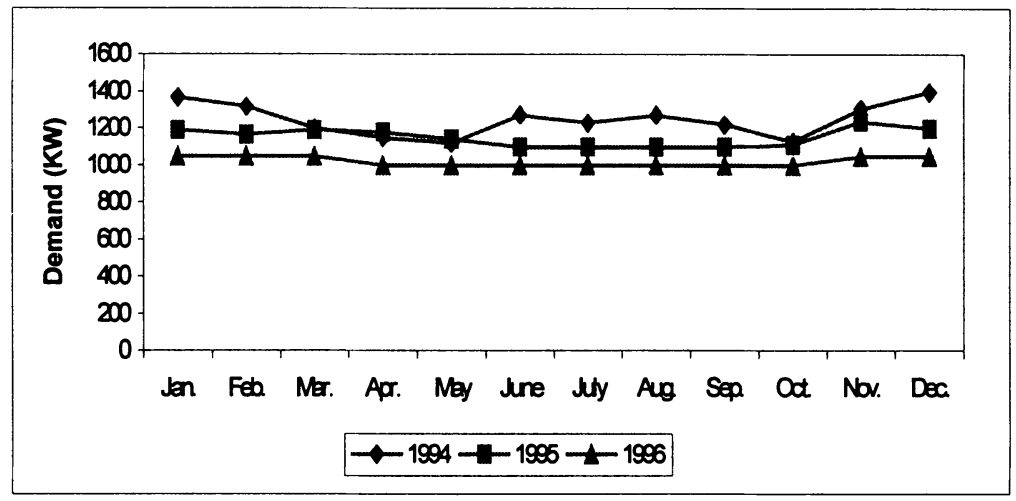

Figure 6 Off-peak demand

\section{CONCLUSIONS}

The implementation of the Building Automation System reduced the average monthly electrical energy consumption from about $20 \mathrm{kWh} / \mathrm{m}^{2}$ in 1994 to about 13 $\mathrm{kWh} / \mathrm{m}^{2}$ in 1996. In 1994 the average monthly demand in peak hours was 33.08 $\mathrm{W} / \mathrm{m}^{2}$ and decreased to $26.59 \mathrm{~W} / \mathrm{m}^{2}$ in 1996 . During the off-peak hours the average monthly demand was in 1994 equal to $67.51 \mathrm{~W} / \mathrm{m}^{2}$ and decreased to $55.19 \mathrm{~W} / \mathrm{m}^{2}$ in 1996. These results show a more efficient way of using electric energy and also the economy obtained, and is more significant if one considers the increase of 5 daily hours in the working period of the building. The annual economy of $27.15 \%$ in the electrical energy expenses was obtained greatly because of the use of more modern technologies in the air conditioning and lighting devices. Nevertheless the energy management technology allows a more rational and efficient utilization of the electric energy in the building.

The reduction of energy consumption was responsible for $16.13 \%$ decrease of the total cost while the reduction of the demand contributed with $11.01 \%$ 
reduction. These values overcome the expectations of cost of energy reductions due to the installation of automated systems that the bibliography ${ }^{7}$ estimates as $10 \%$ for energy consumption. Considering only the economy of the electric expenses and the capital necessary to implement the building automation system, in the order of $\mathrm{R} \$ 400 /$ automated point, the simple payback time is about 3.9 years.

The economy of electric energy created by single actions can be irrelevant, if the total building consumption is considered. However, combining actions in various sectors and the retrofit with the change of habits of all the person who use the building, substantial economy can result. Most of the commercial buildings constructed with conventional technology present a great potential for energy conservation, which can be explored throughout the use of electrical automation ${ }^{5}$. In many cases the capital payback time for the automation system can be quite short.

\section{REFERENCES}

1. Allen - Bradley "Smart Communications Card. Bulletin 1403-5.1" January, 1998;

2. Callahan, MP, et al. "Energy Efficiency for Florida Educational Facilities: The 1996 Energy Survey of Florida Schools" Florida Solar Energy Center, July 1997;

3. Carlson, RA \& Giandomenico, RA, Understanding Building Automation Systems, RS Means Company, Inc, Kingston, 1991;

4. Kettler, JP "Controlling Minimum Ventilation Volume in VAV systems" ASHRAE Trans. May 1998;

5. Lamberts, R, "Eficiência energética de edificaçð̃es" V Encontro Nacional de Instalaçð̃es Elétricas, São Paulo, 1996;

6. Shoureshi, R, Rahmani, $\mathrm{K}$, and Vandoren, V Intelligent Building Control Systems, School of Mechanical Engineering Ray W. Herrick Laboratories, Purdue University, West Lafayette, 1990;

7. Southern California Edison Company, Energy Design Resources - Design Brief - Energy Management Systems, California, USA, 1998. 